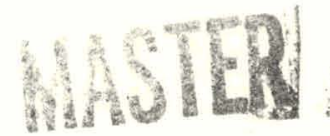

\title{
AMP (Activity Manipulation Program)
}

\author{
W. W. Engle, Jr.
}

\section{OAK RIDGE NATIONAL LABORATORY}




\section{DISCLAIMER}

This report was prepared as an account of work sponsored by an agency of the United States Government. Neither the United States Government nor any agency Thereof, nor any of their employees, makes any warranty, express or implied, or assumes any legal liability or responsibility for the accuracy, completeness, or usefulness of any information, apparatus, product, or process disclosed, or represents that its use would not infringe privately owned rights. Reference herein to any specific commercial product, process, or service by trade name, trademark, manufacturer, or otherwise does not necessarily constitute or imply its endorsement, recommendation, or favoring by the United States Government or any agency thereof. The views and opinions of authors expressed herein do not necessarily state or reflect those of the United States Government or any agency thereof. 


\section{DISCLAIMER}

Portions of this document may be illegible in electronic image products. Images are produced from the best available original document. 
This report was prepared as an account of work sponsored by the United States Government. Neither the United States nor the Energy Research and Development Administration, nor any of their employees, nor any of their contractors, subcontractors, or their employees, makes any warranty, express or implied, or assumes any legal liability or responsibility for the accuracy, completeness or usefulness of any information, apparatus, product or process disclosed, or represents that its use would not infringe privately owned rights. 
Contract No. W-7405-eng-26

Neutron Physics Division

AMP (Activity Manipulation Program)

W. W. Engle, $J x$.

MARCH 1976

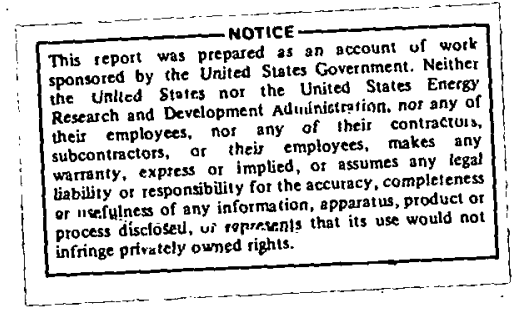

OAK RIDGE NATIONAL IABORATORY

Oak Ridge, Tennessee 37830

operated by

UNION CARBIDE CORPORATJON

for the

ENERGY RESEARCH AND DEVELOPMENT ADMINISTRATION 
TABLE OF CONTENTS

\section{Page}

Introduction - $\ldots \ldots \ldots$

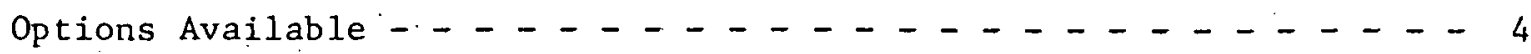

Input $-\ldots \ldots+\ldots-\ldots$

Job Termination $\ldots \ldots \ldots$

Storage Requirements- $\ldots \ldots \ldots \ldots$

Data Set Requirements _ $\ldots \ldots \ldots \ldots$

AMP Special Option - - - - - - - - - - - - - 11 


\section{Introduction}

AMP is a FORTRAN IV program written by G. C. Haynes to handle energygroup structured activity factors such as sources, conversion factors, and response functions, as used by ANISN, DOT III, and other nuclear reactor and shielding codes. Activities may be retrieved from ANISN-type crosssection and activity sets found on cards and tapes, and from tabular-type sets on cards. They may be altered by change of group structure, multiplication by a constant, or multiplication by delta E (the group-energy interval), and then output to ANISN-type cards or tape and tabular-type cards. A full edit of input and output activities is always printed by group and activity number.

For questions and suggestions concerning this code, please contact W. W. Engle, Jr. at 3-1435. 


\section{Options Avatiable}

1. Neutron and gamma-ray activities may be handled separately or as coupled sets.

2. Input and output group structures are independently specified for neutrons and gammas, whether they are coupled or not.

3. Table length for output ANISN-type activity sets is flexible, and table positions not occupled by activity sets are automatically padded with zeros.

4.: Yunched output may be produced in fixed- or free-field FID $\emptyset$ format.

5. ANISN-type output sets may be written as a new data set, or they may be added to the end of an existing data set.

6. If a change of group structure is not required, energy boundaries need not be input $(\mathrm{K} 2=0)$.

7. Input activities may be multiplied by $\Delta \mathrm{E}$ (group interval width).

8. If input and output energy limits do not coincide, the input energy limits may be extended by setting $\mathrm{K} 4=1$. Otherwise, input activities are assumed to be zero outside the input boundary limits.

9. Any number of input ANISN-type data sets may be accessed by negative entries in the $13 \$ \$$ array.

10. Default values have been placed into some input arrays. If these values are satisfactory, these arrays may be omitted. In general, any arrays not specifically required by a problem may also be omitted.

11. Multiple problams may be run by following any previous problem with the title card of a new problem. No data from the previous problem is automatically saved, and all default values apply independently to each problem.

12. ANISN-type activity sets to be output may be printed selectively via the $16 \$ \$$ array. 
Input

A11 input except cross-section ID and title cards are read via FID $\emptyset$ input routines. The first card of a problem must be the title card identifying the fob and/or any output data sets.

Title Card -- Format (20A4)

$1 \$ \$$ Array -- Control Parameters [17 entries]

1. IGMNI $=$ No. of neutron groups input

2. IGMGI $=$ No. of gamma groups input

3. IGMN = No. of neutron groups output

4. IGMG $\varnothing=$ No. of gamma groups output

5. ITLI $=$ Table length of ANISN-type input activity sets

6. ITL $\emptyset=$ Table length of ANISN-type output activity sets

7. NASC $=$ No. of ANISN-type activity sets input from cards

8. NAST = No. of ANISN-type activity sets input from tapes

9. NAM = No. of activities to be retrieved from ANISN-type sets

10. NAT = No. of activities to be entered in tabular format

11. NAS $\emptyset=$ No. of ANISN-type activity sets to be output

12. Kl = ANISN-type activity output logical unit number

$0=$ No ANISN-type output. to tape or cards

$7=$ Punch in fixed FID $\varnothing$ format

$\therefore-7=$ Punch in free FID $\emptyset$ format

4 = Write new data set on undt 4

$-\mathrm{N}=$ Add to end of old data set (KADD) and write on 4. $N$ may be any positive integer except zero or 7 , but

$\therefore \ldots$. if KADD contains a cross-section set larger than ITL $\emptyset * I G M \emptyset U T$ of this problem and $K A D D \neq 4$, the magnitude of $\mathrm{N}$ should be the product of table length and no. of groups for the largest cross-section set on KADD. (This reserves enough core storage to read all data on KADD.)

13. $\mathrm{K} 2=$ Group change trigger $0=$ No effect (no energy boundaries required) 1 = Change group structure $\left(2^{*}, 3^{*}, 4^{*}, 5^{*}\right.$ as required) 
14. $\mathrm{K} 3=\Delta \mathrm{E}$ multiplication trigger

$0=$ No effect

$1=$ Multiply input activities by $\Delta \mathrm{E}$

15. K4 = Energy boundary extension trigger which goes into effect if output energy boundary limits extend beyond input boundary limits

0 = Assume input activities are zero beyond the upper and lower energy limits

1 = Extend upper and lower input boundary limits to coincide with output boundary limfts

16. $\mathrm{KADD}=$ Logical unit number of old ANISN 1ibrary to be added onto if $K 1=-N$. If $K A D D=4$, the old data set is added to. If $K A D D \neq 4$, then KADD is copied onto 4 and output is added. Enter zero if not used $(K 1 \neq-N)$.

17. NDS13 = Number of ANISN-type input data sets specified as negative entries is the $13 \$ \$$ array. If NDS13=0 and NAST $>0$, logica? unit 3 is automatically assigned for input.

Note: The $1 \$ \$$ array is a complete data block and must be terminated with a "T".

2** Array -- Neutron energy boundaries for input activities [IGMNI+1 entr1es] \{omit if IGMNI $=0$ or $\mathrm{K} 2=\mathrm{K} 3=0$ \}

3** - Gamma energy boundaries for input activities [IGMGI+1 entries] \{omit if $\mathrm{IGMGI}=0, \mathrm{IGMG} \emptyset=0$, or $\mathrm{K} 2=\mathrm{K} 3=0$ \}

$4 * *$

-- Neutron energy boundaries for output activities [IGMN $\phi+1$ entries] \{omit if TGMN $\phi=0$ or $\mathrm{K} 2=0$ \} 
-- Input set numbers for ANISN-type activities (used in conjunction with $7 \$ \$$ array). Set numbers 1 through NAST come from cards, and set numbers NASC+1 through NAST come from tapes in orders of input.

[NAM entries] \{omit if NASC+NAST $=0$ \}

-- Input table positions for ANISN-type activities (used in conjunction with $6 \$ \$$ array). Activities 1 through NAM are defined by coincident pairs of entries in the $6 \$ \$$ and $7 \$ \$$ arrays, in the order in which the entries appear. [NAM entries]

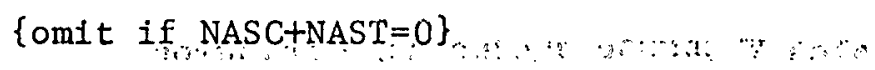

$8 \$ \$$

- Identifies each activity as a source. or a response, where a. 1 means a source and a 2 means a response.

[NAM+NAT entries]

\{omit if all are $1^{\prime}$ 's or $\mathrm{K} 2=0$ \}

$9 \$ \$$

-- Constant multipliers (for all groups) of the input activities. No effect for a constant of 1.0

$$
\begin{aligned}
& \text { [NAM+NAT entries] } \\
& \text { \{omit if all } 1.0^{\prime} \mathrm{s} \text { \} }
\end{aligned}
$$

$10 \$ \$$

-- Output set numbers for ANISN-type activity sets (used in con-. junction with the $11 \$ \$$ array). A zero entry is made for an activity which is not output to an ANISN-type set. Numbers range from 0 through NAS $\emptyset$.

$$
\begin{aligned}
& \text { [NAM+NAT. entrles] } \\
& \text { \{omit if. NAS } \emptyset=0 \text { \}. }
\end{aligned}
$$

11\$\$ -- Output table positions for ANISN-type activity sets (used in confunction with the $10 \$ \$$ array). These numbers may range from 0 through ITL $\varnothing$, and coincident pairs of entries in the $10 \$ \$$ and $11 \$ \$$ arrays define the output activity. sets. Zeros 
should occur in coincident pairs.

[NAM+NAT entries]

\{omit if $N A S \emptyset=0\}$

12\$\$. - Tabular-type output control array. A zero entry prevents output of that activity; a +1 entry causes that activity to be punched in fixed field FID $\varnothing$. A -1 entry for free field.

[NAM+NAT entries]

[omit if all zeros\}

13\$\$ -- Input ID numbers (and data set numbers if NDS13>0) for ANISN-type activity sets from tapes. Negative entries are made for data set logical unit numbers, each followed by ID's pertinent to it. If the first entry is positive, it is assumed that all ID's before the first negative entry are found on logical unit 3.

[NAST+NDS 13 entries]

\{omit if $\mathrm{NAST}=0$ \}

$14 \$$.- ANISN-type output activity set print control, one entry for each set. A zero means do not print, and a 1 means print.

[NAS $\emptyset$ entries]

\{omtt if all zeros\}

Note: Arrays 2 through 14 are members of a data block and this block must be terminated with a "T".

24* and/or 24** - ANISN-type activity sets on cards. Both free field and fixed field FID $\emptyset$ formats may be input, but each time the format changes a new array designator (24* or $24 * *$ ) must precede that data. Although the array number 24 is uesd here, any number from 1 through 99 would be acceptable for input. Each activity set must begin on a separate card, and not on the last card of a previous set.

[ITLI* (IGINI+IGMGI)*NASC entries] 
Note: This is a separate block of data, and it must be terminated with a "T".

\{omit this block if $\mathrm{NASC}=0$ \}

$25^{*}$ or $25^{* *}$ - - Tabular activities to be input on cards. Unlike the $24 *$ array, this entire array is read at one time so that one activity may follow another on the same card. Although the array number 25 is used here, any number (1-99) would suffice.

\section{[(IGMNI+IGMGI)*NAT entries]}

Note: This is a separate block of data, and it must be terminated with a "T".

\{omit this block if NAT=0\}

If $\mathrm{K} 1=4$, or $-\mathrm{N}$, then NAS $\emptyset$ cards of format $(18 \mathrm{X}, 16,12 \mathrm{~A} 4)$ must follow the last array block of a problem. These cards contain the ID numbers and titles of ANISN-type sets to be output to unit 4 or $N$.

\section{Job Termination}

The next problem, if any, is defined by a new title card and its associated data. 'lo terminate the job by a STOP or call1 to EXIT, punch "STOP" or "EXIT" in Col. 1-4 on a separate card following the last card of the input data. Otherwise, the job will terminate by end of record on unit 5 .

\section{Storage Requirements}

AMP uses flexible dimensluning, and the $C \emptyset M M \emptyset N$ block storage in words may be determined by the following equations. This gives the value to be used as the DUMMY (XXXX) dimension and ISIZE=XXXX statement in the main program: 


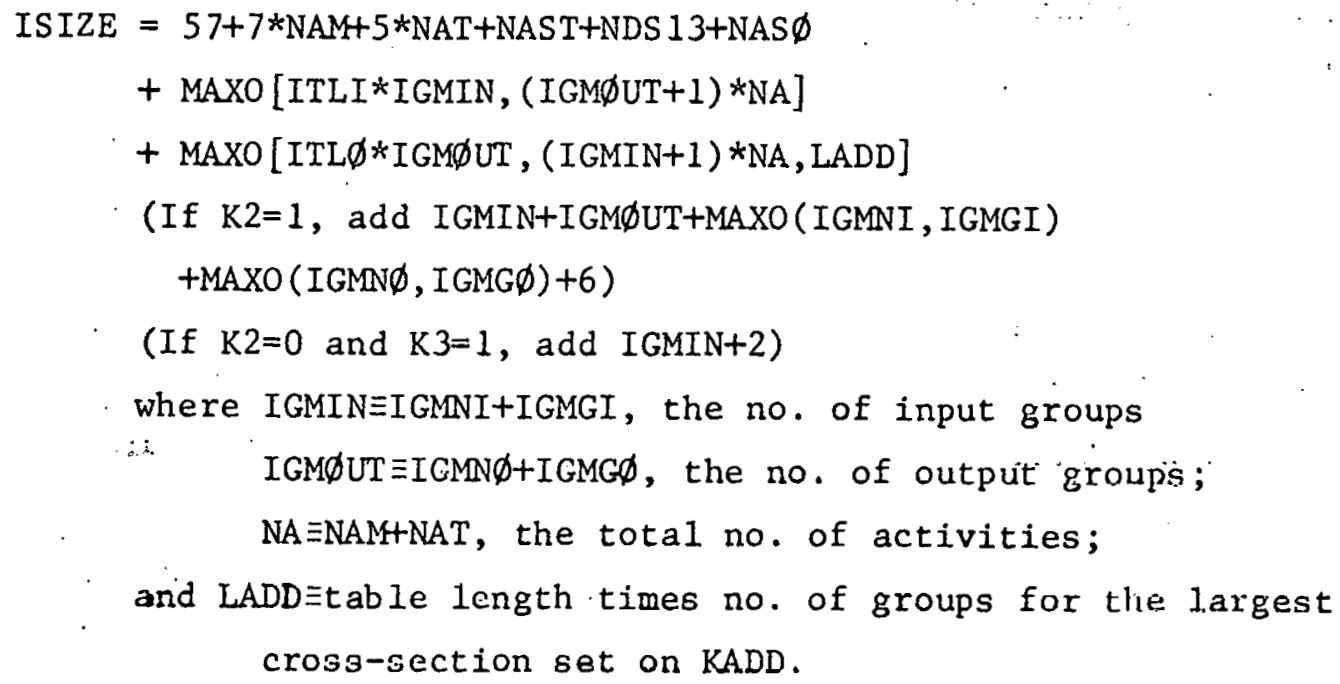

Then REGION. G $\emptyset \geq 80+8 *$ NEDS+ISIZE/256 (K bytes)

where NEDS $\equiv$ No. of extra data sets (other than 5 and 6 ), and it is assumed that each data set required $8 \mathrm{~K}$ for buffers.

Note: ISIZE/256 should be rounded up to the nearest higher even integer.

\section{Data Set Requirements}

Log Unit No.

3 ANISN-type input tape default - required if $N A S T>0$ and the first entry of the $13 \$ \$$ array is positive 


\section{AMP Special Option}

A special option now in AMP allows a user to convert the group structure of a DOT III boundary flux tape by setting NAST $=-1$ and redefining ITLI and ITL $\emptyset$ (ITL $\emptyset=$ ITLI) as the product of the no. of angles and no. of intervals of the boundary fluxes. The group definitions remain the same, but fill the $1 \$ \$$ array with zeroes after NAST.

Other input arrays to be considered are $2 *$ through $5 * *$, and all others are omitted.

Fluxes for each input and each output group are printed for interva1 1 angle 1 , and the sum of these is also printed.

Storage required is:

ITLI* (MAXO ( IGMIN , IGMØUT)+1)

+ IGMNI+IGMGI+IGMN $\varnothing+I G M G \varnothing+89$

$+\operatorname{MAXO}($ IGMNI , IGMGI) +MAXO (IGMN $\varnothing$, IGMG $\emptyset$ ) 


\section{DISTRIBUTION}

1-2. L. S. Abbott

3-4. W. W. Engle

5-6. Central Research Library

7. ORNL - Y-12 Technical Library Document Reference Section

8-9. Laboratory Records Department

10. Laboratory Records, ORNL R.C.

11. ORNL Patent Office

12-13. Technical Information Center, ERDA, ORO 